\title{
Resolution of organ fibrosis
}

\author{
Joon-II Jun and Lester F. Lau
}

Department of Biochemistry and Molecular Cenetics, University of Illinois at Chicago College of Medicine, Chicago, Illinois, USA.

\begin{abstract}
Fibrosis is the excessive accumulation of extracellular matrix that often occurs as a wound healing response to repeated or chronic tissue injury, and may lead to the disruption of organ architecture and loss of function. Although fibrosis was previously thought to be irreversible, recent evidence indicates that certain circumstances permit the resolution of fibrosis when the underlying causes of injury are eradicated. The mechanism of fibrosis resolution encompasses degradation of the fibrotic extracellular matrix as well as elimination of fibrogenic myofibroblasts through their adaptation of various cell fates, including apoptosis, senescence, dedifferentiation, and reprogramming. In this Review, we discuss the present knowledge and gaps in our understanding of how matrix degradation is regulated and how myofibroblast cell fates can be manipulated, areas that may identify potential therapeutic approaches for fibrosis.
\end{abstract}

\section{Introduction}

Fibrosis is the excessive accumulation of extracellular matrix (ECM) that can lead to distortion of tissue architecture and loss of organ function. This pathology commonly results from a wound healing response to repeated or chronic injury or tissue damage, irrespective of the underlying etiology, and can occur in virtually any solid organ or tissue. A broad range of prevalent chronic diseases can give rise to fibrosis, including diabetes, hypertension, viral and nonviral hepatitis, heart failure and cardiomyopathy, idiopathic pulmonary disease, scleroderma, and cancer. Fibrosis resulting from these and other diseases can lead to failure of liver, lung, kidney, heart, or other vital organs as excessive ECM replaces and disrupts parenchymal tissue (1). Consequently, severe fibrosis is estimated to account for up to $45 \%$ of all deaths in the developed world (2). Current therapies for fibrosis are few and of limited efficacy. Therefore, there is an urgent need to understand how fibrosis may regress and to identify potential therapeutic approaches.

Wound healing in any organ generally proceeds through three broad phases that are temporally overlapping but functionally distinct $(3,4)$. Immediately following injury, hemostasis is achieved through the formation of a platelet plug and a fibrin matrix, accompanied by the release of cytokines and chemokines that initiate inflammation and recruit immune cells. This leads to the first phase of healing, the inflammatory phase, wherein infiltration of neutrophils and macrophages combats possible infections and removes tissue and cell debris. Cells undergoing apoptosis and the immune cells they recruit promote new tissue formation by producing proinflammatory, vasoactive, and profibrotic effectors, including TGF- $\beta 1$, PDGF, TNF- $\alpha$, IL-6, and IL-13, to prompt the proliferative phase of healing (5-7). TGF- $\beta 1$ plays a particularly prominent role in inducing the differentiation of precursor cells into myofibroblasts, which rapidly produce a prodigious amount of ECM to maintain the integrity of the injured tissue during repair and to enhance cell proliferation for granulation tissue formation

Conflict of interest: The authors have declared that no conflict of interest exists Reference information: J Clin Invest. 2018;128(1):97-107.

https://doi.org/10.1172/JCI93563. or parenchymal regeneration (Figure 1). In the final maturation phase, the provisional ECM is degraded and remodeled to rebuild the parenchymal tissue architecture. Dysregulation of these processes or repeated or chronic injury allows inadequate opportunity for the ECM to be resolved as myofibroblasts are relentlessly stimulated to produce ECM. Over time, the accumulated ECM begins to form a fibrotic lesion. With some exceptions, fibrosis is associated with chronic inflammation, which drives the production of profibrotic growth factors (3).

The principal cell type that produces ECM to form fibrotic lesions is the myofibroblast, which exhibits features of both smooth muscle cells and fibroblasts, and is characterized by a prominent rough endoplasmic reticulum, stress fibers, enlarged nucleolus, and expression of $\alpha$-smooth muscle actin ( $\alpha \mathrm{SMA})$ and other contractile proteins (8). Myofibroblasts produce interstitial or fibrillar ECM largely composed of collagen I and III, as well as myriad other ECM proteins, including an alternatively spliced form of fibronectin with an extra domain A (EDA-fibronectin) that is important for TGF- $\beta 1$-induced myofibroblast differentiation (9). In the early granulation tissue, there is a population of fibroblastic cells that express collagen I and III, termed proto-myofibroblasts, that can be fully differentiated into myofibroblasts upon stimulation by TGF- $\beta 1(8,10)$. The sources of myofibroblast precursors are heterogeneous and have been controversial (Figure 1), although recent data indicate that resident fibroblasts and pericytes are major contributors $(11,12)$, with mesenchymal stem cells also playing a role $(13,14)$. The mechanisms that trigger fibrogenesis have been discussed in several excellent recent reviews $(7,15,16)$.

\section{Reversibility of organ fibrosis}

Although fibrosis was once thought to be irreversible, there is now a growing body of evidence suggesting that fibrosis is reversible in human fibrotic diseases under some circumstances. Most information on fibrosis regression comes from studies in animal models, where resolution can occur in most cases if the underlying etiology is eliminated. In contrast to animal models where the cause of injury is well defined, human fibrotic diseases are often multifactorial and eradication of the injurious stimuli may not be possible. More- 


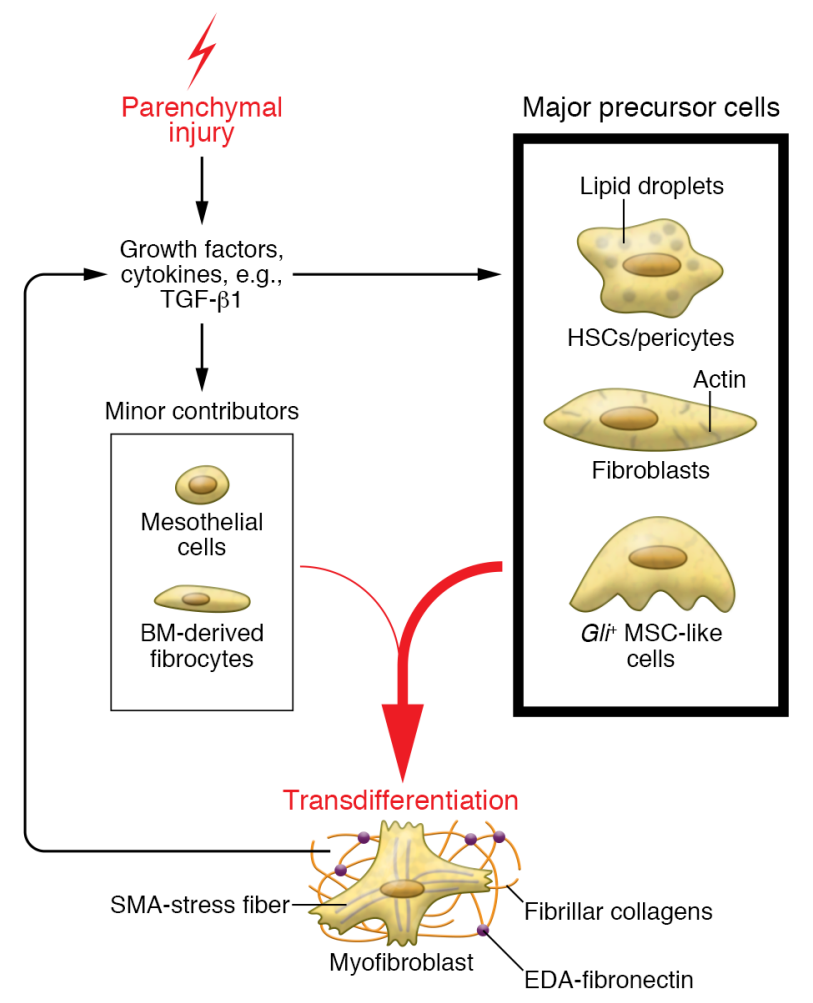

over, available animal models often do not fully recapitulate the relevant human disease, and thus treatment strategies that lead to fibrosis regression in animal models may not directly translate into therapy in humans. In the section below, we briefly summarize the etiologies associated with fibrosis in parenchymal tissues, the evidence for fibrosis reversibility, and relevant experimental models.

Liver fibrosis. The primary causes of liver fibrosis are etiologies that drive chronic inflammation, including viral and parasitic infections, excessive alcohol consumption, and nonalcoholic steatohepatitis. The most compelling evidence for the resolution of organ fibrosis in humans is observed in the liver. Patients with liver fibrosis associated with hepatitis B virus (HBV) or HCV infection treated with antiviral therapies have shown fibrosis regression and histological improvements even in cases of cirrhosis (17-19). Liver fibrosis triggered by schistosomiasis, one of the most common causes of liver fibrosis worldwide, is also thought to regress upon treatment of infection $(20,21)$. Common experimental rodent models for liver fibrosis include administration of a hepatotoxin (e.g., carbon tetrachloride $\left[\mathrm{CCl}_{4}\right]$ ) to induce acute hepatocellular injury or bile duct ligation (BDL) to induce cholestasis, resulting in pericentral or periportal liver fibrosis, respectively. Genetic lineage tracing studies have found that the vast majority of myofibroblasts in the fibrotic rodent liver are derived from hepatic stellate cells (HSCs), irrespective of etiology $(22,23)$. HSCs are normally quiescent, pericyte-like vitamin A storage cells located in the space of Disse between hepatocytes and the fenestrated sinusoid. In addition, portal fibroblasts, bone marrow-derived fibrocytes, and $\mathrm{Gli}^{+}$mesenchymal stem cell-like cells also contribute to hepatic myofibroblasts $(13,23)$, whereas mesothelial cells can give rise to HSCs and myofibroblasts through mesothelial-to-mesenchymal transition (MMT) (24).
Figure 1. Transdifferentiation of precursor cells into fibrogenic myofibroblasts. Upon parenchymal injury, the wound-healing response leads to the release of fibrogenic growth factors and cytokines, the most prominent of which is TCF- $\beta 1$. These factors drive the transdifferentiation and proliferation of precursor cells into myofibroblasts. Major precursors of myofibroblasts are cells of mesenchymal origin, including resident fibroblasts, pericytes, and Clit mesenchymal stem cell-like (MSC-like) cells. In some cases, myofibroblasts may be derived from bone marrow-derived (BM-derived) fibrocytes or through mesothelial-to-mesenchymal transition (MMT). Myofibroblasts produce ECM comprising fibrillar collagens that undergo extensive cross-linking and EDA-fibronectin, which promotes TCF- $\beta 1$-induced transdifferentiation.

Lung fibrosis. Fibrosis of the lung is associated with diverse etiologies, including scleroderma (systemic sclerosis), sarcoidosis, infections, and exposure to toxicants or radiation. Idiopathic pulmonary fibrosis (IPF) is the most common form of idiopathic interstitial pneumonia and is usually fatal, with a median survival of 2 to 3 years. IPF is not associated with substantial inflammation, and antiinflammatory therapy is ineffective (25). In 2014, the FDA granted fast-track approval for the profibrotic signaling inhibitors pirfenidone and nintedanib for treating IPF on the basis of their slowing of lung function decline as measured by forced vital capacity and reduced all-cause mortality (26). However, the efficacy of these drugs to promote fibrosis resolution in IPF has not been demonstrated. The most common experimental mouse model for lung fibrosis is intratracheal administration of the chemotherapeutic drug bleomycin, which induces inflammation followed by fibrosis (27). Spontaneous resolution of fibrosis with restitution of tissue architecture occurs in this model upon cessation of further bleomycin-induced injury. Various studies have found that myofibroblasts in the fibrotic lung are largely derived from pericytes, with contribution from mesothelial cells through MMT $(13,28-31)$.

Kidney fibrosis. Fibrosis is a major complication in all forms of chronic kidney disease (CKD), of which diabetes and hypertension are principal causes. Even though the initial injury to the kidney may affect the glomerulus, tubules, or interstitium, the final outcome of all progressive CKD is the formation of tubulointerstitial fibrosis $(32,33)$. Kidney fibrosis in patients with diabetic nephropathy can be ameliorated by pancreas transplantation (34, 35), suggesting that established kidney fibrosis can be reversible to some extent (36). A common rodent model of renal fibrosis is unilateral ureteral obstruction (UUO), in which one ureter is ligated while the other is left as control, causing fibrosis to develop within 
Table 1. Targeting regulators of ECM metabolism in fibrosis resolution in animal models

\begin{tabular}{|c|c|c|c|c|c|}
\hline ECM target & Liver & Lung & Kidney & Heart & References \\
\hline MMP1 overexpression & Attenuated thioacetamide fibrosis & & & $\begin{array}{l}\text { Attenuated } \\
\text { cardiac fibrosis }\end{array}$ & 52,53 \\
\hline MMP2 KO & $\begin{array}{c}\text { Exacerbated fibrosis in } \mathrm{CCl}_{4} \\
\text { and BDL model }\end{array}$ & & & & 159 \\
\hline ММРЗ КО & & Protection from bleomycin fibrosis & & & 160,161 \\
\hline MMP7 KO & & Protection from bleomycin fibrosis & & & 160,161 \\
\hline MMP12 KO & & No effect on fibrosis & No effect on UUO fibrosis & & $167-169$ \\
\hline MMP13 & $\begin{array}{l}\text { Reduced fibrosis in KO mice; } \\
\text { overexpression accelerated resolution }\end{array}$ & $\begin{array}{l}\text { Less fibrosis in radiation injury; } \\
\text { no effect in hyperoxia injury } \\
\text { in KO mice }\end{array}$ & & & $170-173$ \\
\hline МMP19 КО & Protected from $\mathrm{CCl}_{4}$ fibrosis & & & & 174 \\
\hline LOXL2 mAb & Reduction in fibrosis & Reduction in fibrosis & & Reduction in fibrosis & $62-64$ \\
\hline TG2 KO & No effect in $\mathrm{CCl}_{4}$ fibrosis & Reduction in bleomycin fibrosis & & & 66,67 \\
\hline
\end{tabular}

7 days (37). Myofibroblasts in kidney fibrosis are derived primarily from resident fibroblasts, bone marrow-derived fibrocytes, and $\mathrm{Gli}^{+}$progenitors $(13,38)$. Interestingly, recent studies have indicated that tubular epithelial cells can undergo partial epithelial-to-mesenchymal transition, leading to recruitment of inflammatory cells and release of fibrogenic cytokines, which exacerbate myofibroblast activation and fibrogenesis $(39,40)$.

Cardiac fibrosis. Cardiac fibrosis results from pathological myocardial remodeling triggered by heart diseases of nearly all etiologies (41). In contrast to organs discussed above, the parenchymal cells in the heart are muscle cells (cardiomyocytes) rather than epithelial cells and display very limited regenerative capacity. Consequently, extensive scarring is necessary to prevent rupture following myocardial infarction and other injuries. Nevertheless, in patients with hypertension and left ventricular hypertrophy or stiffness, regression of biopsy-proven cardiac fibrosis was observed after treatment with the hypotensive drugs lisinopril or losartan $(42,43)$. Experimental models of cardiac fibrosis include permanent occlusion of the left anterior descending (LAD) coronary artery to induce myocardial infarction, and transverse aortic constriction (TAC) to trigger pressure overloadinduced cardiac hypertrophy. Regression of collagen deposition occurs after constriction is removed in TAC-treated mice (44) and in hypertensive rats following treatment with angiotensin-converting enzyme inhibitors $(45,46)$. Genetic lineage tracing found that myofibroblasts in the injured heart are primarily derived from resident fibroblasts $(13,47)$, which constitute a significant percentage of cardiac cells (48).

\section{Degradation of the fibrotic ECM}

Since fibrosis develops as a healing response to injury that leads to excessive production of ECM by myofibroblasts, effective resolution of fibrosis requires three critical components: (a) eradication of the cause of injury; (b) degradation and removal of the fibrotic ECM; and (c) elimination of fibrogenic myofibroblasts. Treating the cause of injury is perhaps the most efficacious approach to fibrosis resolution, as exemplified by antiviral treatment of HBV-induced liver fibrosis $(17,18)$. In the absence of further injury, matrix remodeling may proceed as part of wound healing and eventually lead to fibrosis resolution. However, when etiology is unclear or effective treatments for the underlying cause of injury are unavailable, tackling the fibrotic ECM directly may help to ameliorate the pathological effects of the lesion (Table 1).

There are two major types of ECM: basement membrane, which forms a lattice of support for epithelial and endothelial cells, and interstitial ECM secreted mainly by fibroblasts in the connective tissue. The basement membrane is composed of collagen IV, laminins, heparan sulfate proteoglycans, and proteins such as nidogen and entactin, whereas fibrotic ECM adopts more interstitial-like characteristics, with a preponderance of fibrillar collagen I and III, as well as fibronectin, hyaluronan, elastin, and various proteoglycans (49). As fibrosis progresses, secreted collagen becomes more heavily cross-linked by lysyl oxidase (LOX) and tissue transglutaminase (TG2), thereby forming a rigid structure that is more resistant to proteolytic degradation and can alter cellular function and tissue architecture. Tg mice expressing a nondegradable form of collagen I displayed persistent HSC activation and $\mathrm{CCl}_{4}$-induced liver fibrosis, underscoring the importance of ECM degradation in fibrosis resolution (50).

The most important enzymes contributing to the extracellular pathway of collagen degradation are matrix metalloproteinases (MMPs), a family of $\mathrm{Zn}^{++}$- and $\mathrm{Ca}^{++}$-dependent endopeptidases produced by a broad spectrum of cell types. Intact fibrillar col- 


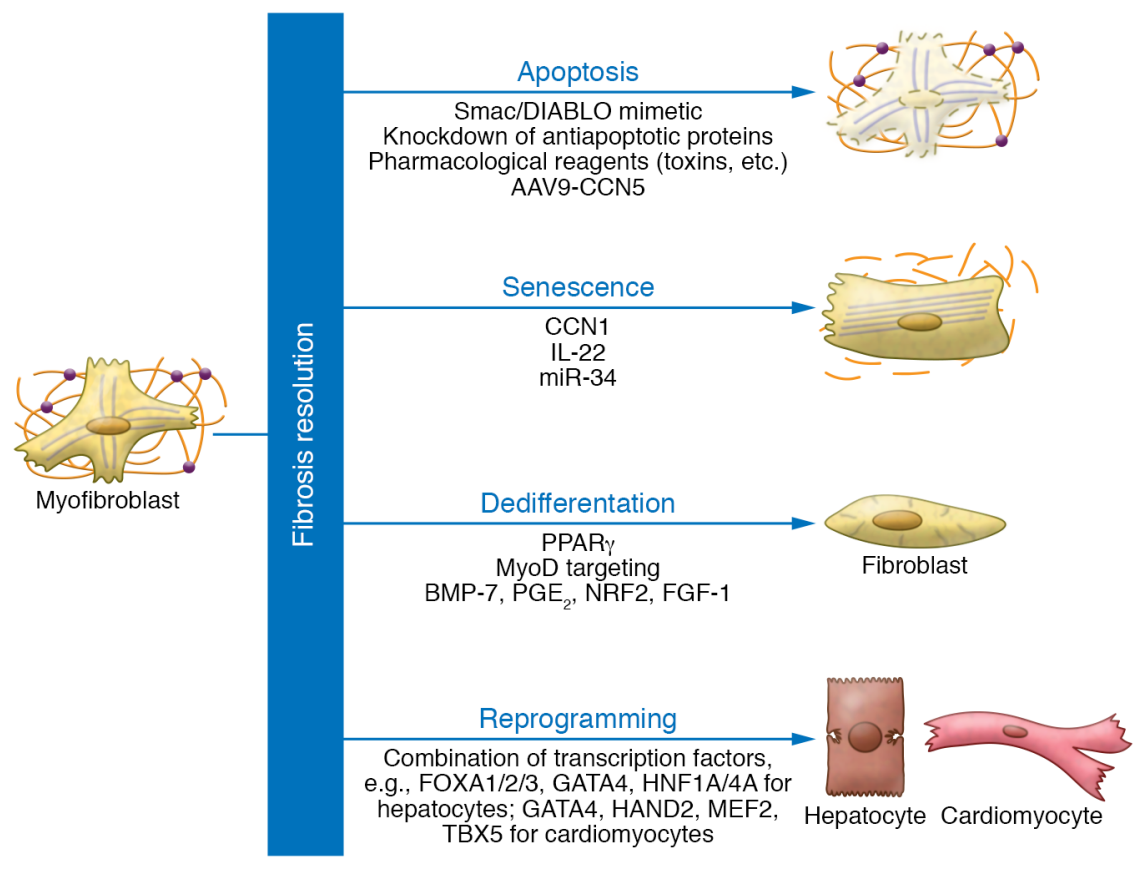

Figure 2. Fate of myofibroblasts during fibrosis resolution. Fibrogenic myofibroblasts can be eliminated during fibrosis resolution through one of several alternative cell fates: apoptosis, senescence, and dedifferentiation. Cellular lineage reprogramming also serves as an alternative route to eliminate myofibroblasts. These cell fates are not mutually exclusive and can be driven through genetic or pharmacological manipulations to promote fibrosis resolution. lagen can be degraded by collagenases (MMP1, MMP8, MMP13, MMP18) and two membrane-anchored MMPs (MMP14 and MMP16) (51), with MMP1, MMP13, and MMP14 being the most critical in fibrotic matrix degradation (52-54). However, some MMPs can promote fibrosis through activities unrelated to direct degradation of ECM (55). MMP activities are inhibited by tissue inhibitors of metalloproteinases (TIMPs) through their binding in a 1:1 stoichiometric ratio (56). In contrast to the $25 \mathrm{MMPs}$ in mammals, there are 4 TIMPs (TIMP1-TIMP4) that can preferentially interact with distinct subsets of MMPs. The resultant MMP-TIMP complexes are recognized by scavenger receptors and engulfed by macrophages. Paradoxically, both overexpression and KO of Timp1 in mice resulted in more severe liver fibrosis $(57,58)$, and Timp3-KO mice experienced aggravated fibrosis despite an overall increase in MMP activity (59). Since TIMPs can regulate cell growth, migration, and survival (60), they may regulate cellular processes that directly or indirectly influence myofibroblast activation and ECM turnover.

LOX and its homologs, LOX-like enzymes 1-4 (LOXL1-LOXL4), are extracellular copper-dependent enzymes that catalyze aldehyde formation from lysine residues in collagen and elastin precursors (61). LOXL2 inhibition was shown to attenuate and reverse fibrosis of the heart, lung, and liver in experimental models, fueling considerable enthusiasm for LOXL2 blockade as a therapeutic approach (62-64). However, a recent clinical trial using the humanized $\mathrm{mAb}$ simtuzumab to inhibit LOXL2 activity did not improve progression-free survival in IPF patients (65). It is likely that the mouse bleomycin model does not adequately recapitulate human IPF, the etiology of which is unknown. TG2 can also cross-link proteins to form inter- and intramolecular bonds between lysine and glutamine residues. Although TG2-null mice developed reduced lung fibrosis, they did not show any difference in the extent or reversibility of $\mathrm{CCl}_{4}$-induced liver fibrosis, suggesting that the effects of TG2 on matrix stability are tissue-specific $(66,67)$.
In addition to the extracellular pathways for collagen degradation, macrophages and myofibroblasts can internalize intact or fragmented collagen for degradation. For example, integrins $\alpha_{2} \beta_{1}$ and $\alpha_{3} \beta_{1}$, as well as the fibroblast-derived transmembrane urokinase plasminogen activator receptor-associated protein (uPARAP or Endo180), can bind and internalize fibrillar and nonfibrillar collagens to the lysosome for degradation (51). uPARAP-deficient mice exhibited increased total lung collagen after bleomycin injury (68). Uptake of fragmented collagen in macrophages depends on the extracellular glycoprotein milk fat globule-epidermal growth factor 8 (MFGE8), and Mfge8-null mice develop aggravated pulmonary fibrosis induced by bleomycin (69). MFGE8 also promotes inflammation resolution by inhibiting inflammasome-induced IL-1 $\beta$ production (70) and stimulating the clearance of apoptotic cells by acting as a bridging molecule that binds apoptotic cells and the phagocytic receptor integrin $\alpha_{\mathrm{v}} \beta_{3}$ on macrophages (71).

Another critical component in ECM metabolism is the protean function of macrophages, which are recruited during the inflammatory phase and produce profibrotic growth factors, including TGF- $\beta 1$. Selective depletion of macrophages during $\mathrm{CCl}_{4}$-induced injury resulted in reduced fibrosis, whereas deletion of macrophages in the recovery phase impaired ECM degradation and fibrosis resolution, indicating that macrophages have both proand antifibrotic effects at different phases of injury and repair (72). During liver injury, inflammatory cytokines such as CCL2 (also known as MCP-1) recruit Ly6 $\mathrm{C}^{\text {hi }}$ monocytes and macrophages, but these macrophages switch to a Ly6 $\mathrm{C}^{\text {lo }}$ phenotype and produce MMPs during fibrosis resolution (73). Selective depletion of Ly $6 \mathrm{C}^{\text {lo }}$ macrophages during fibrosis regression results in impaired scar remodeling, consistent with the matrix-degrading functions of these macrophages. Macrophage therapy using mature macrophages, but not their monocyte precursors, reduced liver fibrosis in mice by expressing MMP13 and MMP9 (74). In addition, the antifibrotic functions of macrophages may be mediated in part 
Table 2. Effects of manipulating myofibroblast cell fate in animal models of fibrosis resolution

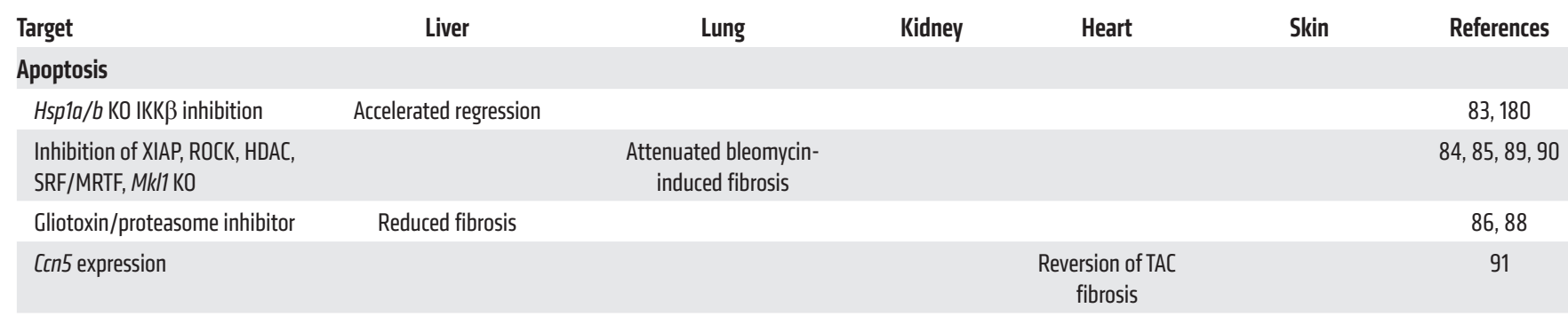

\section{Senescence}

\begin{tabular}{|c|c|c|c|c|c|}
\hline p53/p16 КО & Exacerbated $\mathrm{CCl}_{4}$ fibrosis & $\begin{array}{l}\text { Enhanced UUO } \\
\text { fibrosis }\end{array}$ & $\begin{array}{l}\text { Aggravated TAC } \\
\text { fibrosis }\end{array}$ & & $95,104-106$ \\
\hline $\begin{array}{l}\text { CCN1 (protein delivery } \\
\text { or gene expression) }\end{array}$ & $\begin{array}{l}\text { Reduced } \mathrm{CCl}_{4} \text { and } \mathrm{BDL} \text { fibrosis, } \\
\text { accelerated resolution }\end{array}$ & & $\begin{array}{l}\text { Reduction of TAC } \\
\text { fibrosis }\end{array}$ & $\begin{array}{l}\text { Accelerated resolution } \\
\text { in wound healing }\end{array}$ & $96,101,102,105$ \\
\hline $\begin{array}{l}\text { IL-22 (protein or gene } \\
\text { expression) }\end{array}$ & $\begin{array}{l}\text { Reduced fibrosis and accelerated } \\
\text { resolution of } \mathrm{CCl}_{4} \text { fibrosis }\end{array}$ & & & & 103 \\
\hline miR-34 & & & & & 113 \\
\hline
\end{tabular}

\section{Dedifferentiation}

PPAR $\gamma$ activation

(nitrated fatty acids)

BMP7

FGF-1

\section{Suppression of fibrosis}

Reduced severity and promoted fibrosis reversal

Reduced TCF- $\beta$-induced fibrosis
Reversal of chronic renal injury

122,123

\section{Reprogramming}

Combination of transcription Attenuation of $\mathrm{CCl}_{4}$-induced factors

fibrosis

$134,136,137$ through their expression of the angiogenic factor VEGF. Ablation of VEGF specifically in myeloid cells, including macrophages, prevented resolution of $\mathrm{CCl}_{4}$-induced liver fibrosis concomitant with reduced expression of $M m p 2$ and Mmp14 in endothelial cells and increased expression of Timp1 and Timp2 (75). These results point to multiple roles of macrophages in fibrosis resolution through degradation of the ECM.

\section{Elimination of the fibrogenic myofibroblasts}

Since activated myofibroblasts are the primary sources of the fibrotic ECM, elimination of these cells is a prerequisite for sustained fibrosis resolution. Fibrogenic myofibroblasts can be eliminated through several alternative cell fates, which may be exploited for potential therapeutic intervention (Figure 2 and Table 2).

Myofibroblast apoptosis. It has been well established that myofibroblasts can undergo apoptosis during fibrosis resolution, and the apoptotic cell debris is removed by macrophages and dendritic cells $(76,77)$. Apoptosis is coordinated by two major pathways: the extrinsic pathway, involving death receptors (e.g., TNFR-1 and Fas); and the intrinsic pathway, mediated through mitochondria, resulting in activation of caspases (78). Fas ligand-expressing immune cells induce Fas-dependent myofibroblast apoptosis during the resolution of lung fibrosis, underscoring the importance of the extrinsic apoptotic pathway (79). However, myofibroblasts of fibrotic tissues often exhibit increased resistance to apoptosis, most commonly by overexpressing antiapoptotic and prosurvival proteins. Some of the cytokines and growth factors expressed in the inflammatory milieu can activate $\mathrm{NF}-\kappa \mathrm{B}$, a master transcription factor that promotes cell survival through activation of antiapoptotic genes (80). Moreover, both TGF- $\beta 1$ and endothelin-1 (ET-1), potent activators of myofibroblastic differentiation, can promote resistance to apoptosis by activating FAK and PI3K/AKT (81).

In the liver, activated HSCs are resistant to many apoptotic stimuli, in part because of upregulation of the antiapoptotic proteins BCL-2 and HSP1A/B (82, 83). Ablation of HSP1A/B renders HSCs more susceptible to TNF- $\alpha$-induced apoptosis, and

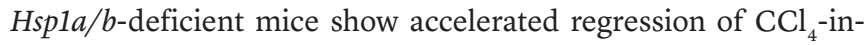
duced liver fibrosis. In addition, ECM stiffening in fibrotic conditions can modulate fibroblast resistance to apoptosis through a mechanotransduction pathway involving Rho/ROCK and the mechanosensitive transcription factor megakaryoblastic leukemia 1 (MKL1), resulting in upregulation of profibrotic and prosurvival genes $(84,85)$. Inhibition of ROCK by fasudil or genetic ablation of $M k l 1$ protected mice from experimental lung fibrosis (84).

Several pharmacological strategies targeting antiapoptotic mechanisms of myofibroblasts can reduce the formation of fibrosis and accelerate resolution of pre-established fibrosis. Treatment with an IKB kinase (IKK) inhibitor (sulfasalazine), a 
proteasome inhibitor (bortezomib), or the fungal toxin gliotoxin enhanced myofibroblast apoptosis and reduced liver fibrosis (8688). Administration of suberoylanilide hydroxamic acid, a histone deacetylase (HDAC) inhibitor, drove apoptosis in IPF patient myofibroblasts in vitro by upregulating proapoptotic BAK and downregulating antiapoptotic BCL-XL, and ameliorated bleomycin-induced pulmonary fibrosis in mice (89). Likewise, inhibiting the caspase inhibitor XIAP, which is highly expressed in fibrotic lung fibroblasts, protected mice from bleomycin-induced lung fibrosis (90). Expression of the matricellular protein CCN5 in the heart reversed pre-established cardiac fibrosis in part by inducing myofibroblast apoptosis through activation of the intrinsic pathway (91). Together, these results suggest that targeting myofibroblast apoptosis can alleviate fibrosis burden as a potential therapeutic approach for the treatment of organ fibrosis.

Myofibroblast senescence. Cellular senescence is an essentially irreversible form of cell cycle arrest. A variety of cellular injuries or stresses, including DNA damage, oncogene activation, oxidative stress, and telomere erosion, can trigger the p53/p21 and/or the $\mathrm{p} 16^{\mathrm{INK} 4 \mathrm{a}} / \mathrm{pRb}$ tumor suppressor pathways to establish and maintain senescence $(92,93)$. Senescent cells cease to proliferate and exhibit the senescence-associated secretory phenotype (SASP), a characteristic gene expression profile that includes upregulation of ECM-degrading enzymes such as MMPs $(93,94)$. In myofibroblasts of the liver and skin, SASP also includes downregulation of collagen and TGF- $\beta 1(95,96)$. Thus, by undergoing senescence, myofibroblasts switch from being proliferating, ECM-producing profibrotic cells to being growth-arrested, ECM-degrading antifibrotic cells. These cells are ultimately eliminated by NK cells, $\mathrm{CD}^{+} \mathrm{T}$ cells, and macrophages, which selectively target senescent cells for immunological clearance $(95,97,98)$.

Myofibroblast senescence has been shown to play important roles in fibrosis resolution in multiple organ systems, including the liver, skin, heart, kidney, and lung (Table 2), underscoring its broad significance. Senescent myofibroblasts can be recognized as $\alpha$ SMA-positive cells that express senescence markers, including $\mathrm{p} 21, \mathrm{p} 16^{\mathrm{INK} 4 \mathrm{a}}$, and senescence-associated $\beta$-galactosidase (SA- $\beta$ gal) (95). Mice with genetic ablation of p53 and p16 $6^{\text {INK4a }}$ suffered exacerbated liver fibrosis when subjected to $\mathrm{CCl}_{4}$-induced injury concomitant with reduced myofibroblast senescence, elevated $T g f b 1$ expression, and reduced MMP expression (95).

The secreted matricellular protein CCN1 (also named Cyr61) is upregulated during injury repair in many tissues and has been shown to regulate myofibroblast senescence in diverse contexts of injury repair $(99,100)$. CCN1 induces myofibroblast senescence through direct binding to integrin $\alpha_{6} \beta_{1}$ on the cell surface, thus activating Rac1 and NADPH oxidase 1 to generate sustained accumulation of ROS, leading to activation of p53 and p16 ${ }^{\text {INK4a }}$ and senescence (96). In excisional skin wounds, CCN1 is required for myofibroblast senescence at the maturation phase of healing to restrict fibrosis (96). Skin wounds of mice that expressed a mutant CCN1 unable to bind integrin $\alpha_{6} \beta_{1}$ did not exhibit senescent cells; lacked expression of SASP, including MMPs; and suffered exacerbated fibrosis. Moreover, topical application of recombinant CCN1 protein to cutaneous wounds of CCN1 mutant mice restored induction of myofibroblast senescence and reduced collagen deposition to dampen fibrosis (96).
Similarly, deletion of $C c n 1$ specifically from hepatocytes, the major Con1-expressing cell type in the liver, resulted in reduced myofibroblast senescence, diminished expression of MMPs, and exacerbated fibrosis upon hepatic injury due to either hepatotoxin $\left(\mathrm{CCl}_{4}\right)$ or cholestasis (BDL) (101). Conversely, mice overexpressing $C c n 1$ in hepatocytes showed increased myofibroblast senescence and reduced fibrosis with elevated expression of SASP. CCN1 also induces cellular senescence and expression of SASP in activated HSCs and portal fibroblasts. Injection of CCN1 protein accelerated resolution of pre-established liver fibrosis (101), and adenoviral Ccn1 expression attenuated BDL-induced fibrosis (102). In addition to CCN1, IL-22 can also induce senescence in activated HSCs via p53 activation through a STAT3-dependent pathway, leading to increased production of MMPs and reduced fibrosis (103). Consistently, ectopic expression of IL-22 reduced $\mathrm{CCl}_{4}$-induced liver fibrosis and accelerated resolution of fibrosis during recovery (103).

In the heart, senescent cardiac fibroblasts accumulate after LAD ligation-induced myocardial infarction or TAC-induced cardiac hypertrophy and fibrosis $(104,105)$. Genetic ablation of p53 and/or p16 ${ }^{\text {INK4a }}$ in mice abrogated the accumulation of senescent myofibroblasts, decreased expression of MMPs, and aggravated fibrosis $(104,105)$. Cardiac-specific expression of Ccn1 engendered increased cardiofibroblast senescence and reduced perivascular fibrosis with improved cardiac function after TAC (105). In the kidney, both tubular epithelial cells and interstitial fibroblasts undergo senescence upon UUO-induced injury (106). Mice with ablation of $16^{\text {INK4a }}$ do not exhibit SA- $\beta$-gal-positive senescent cells and fibrosis is enhanced, consistent with senescence playing an antifibrotic role (106). Interestingly, inducing senescence in renal epithelial cells leads to enhanced fibrosis in aristolochic acid-induced renal fibrosis (107). Since epithelial cells are not major producers of the fibrotic ECM, senescence in these cells is unlikely to terminate fibrogenesis. Instead, senescence in epithelial cells may potentially aggravate fibrosis through the expression of proinflammatory cytokines $(92,93)$.

Cellular senescence in epithelial cells versus myofibroblasts is also likely to cause divergent effects in the lung. SA- $\beta$-gal-positive senescent cells are observed predominantly in alveolar and bronchial epithelial cells, but also in lung fibroblasts (108-112). Recent studies showed that the microRNA miR-34a is upregulated in lung myofibroblasts of IPF patients and in bleomycin-injured mice, and induces senescence of lung fibroblasts (113). Young mice with miR-34a ablation accumulated fewer senescent cells and suffered exacerbated pulmonary fibrosis upon bleomycin exposure, suggesting that miR-34a inhibits lung fibrosis by inducing lung myofibroblast senescence (113). In contrast to these antifibrotic effects, miR-34a is profibrotic when it is highly expressed in alveolar epithelial cells in aged mice, but not when it is expressed in fibroblasts (114). These results suggest that senescence in myofibroblasts has an antifibrotic effect, whereas senescence in lung epithelial cells may trigger further damage and exacerbate fibrosis $(114,115)$. Recent studies also show that selective elimination of senescent cells by senolytic agents or suicide gene expression improved lung functions, although lung fibrosis was apparently unaltered (111). In this model, both senolytic agents and suicide gene expression targeted senescent cells generally and did not distinguish between senescent epithelial cells and myofibroblasts. 
Myofibroblast dedifferentiation. Fibrogenic myofibroblasts can revert to an inactive phenotype characteristic of myofibroblast precursor cells during fibrosis resolution. $\mathrm{In}_{\mathrm{CCl}_{4}}$-induced or alcohol intoxication-induced liver fibrosis, regression is accompanied by the reversion of activated HSCs to an inactive, quiescent-like phenotype $(83,116)$. HSCs are normally quiescent cells with vitamin A and lipid stores that express the transcription factor PPAR $\gamma$, which regulates the expression of genes relevant to adipogenesis. HSC differentiation into myofibroblasts is accompanied by PPAR $\gamma$ depletion, whereas activation or overexpression of PPAR $\gamma$ results in the phenotypic reversal of activated HSCs to quiescent cells in vitro $(117,118)$. When activated HSCs revert to an inactivated phenotype during fibrosis resolution, they re-express PPAR $\gamma$ and downregulate the expression of fibrogenic genes, including Acta2 (encoding $\alpha$ SMA), Col1a1, Col1a2, Timp1, and Tgfbr1 (83). Interestingly, inactivated HSCs are more responsive to further fibrogenic stimuli and express fibrogenic genes more strongly when stimulated by TGF- $\beta$ than naive HSCs that have not been previously activated $(83,116)$. Therefore, recovering livers are likely more susceptible to recurring fibrogenic insults.

In the lung, lipofibroblasts (lipid interstitial cells) transdifferentiate into myofibroblasts in response to hyperoxia or nicotine exposure $(119,120)$. As in HSCs, depletion of PPAR $\gamma$ in lung fibroblasts induced a profibrotic phenotype, and activation of PPAR $\gamma$ promoted dedifferentiation in lung myofibroblasts (121). Lineage tracing studies show that lipofibroblasts are contributing precursors of myofibroblasts after bleomycin-induced injury, and some of the myofibroblasts revert back to lipofibroblast-like cells following fibrosis resolution, with downregulation of $\alpha$ SMA and upregulation of lipofibroblast markers (31). Myofibroblast dedifferentiation is also observed in the heart, where lineage tracing showed that cardiac myofibroblasts are derived from periostin-expressing $T c f 21^{+}$resident fibroblasts (47). Periostin-traced myofibroblasts revert to a less active state upon injury resolution, losing expression of myofibroblast-associated genes including Acta2, collagen, and fibronectin, but regaining expression of genes associated with the fibroblast phenotype including $T c f 21$ and $P d g f a$ (47).

The observation that myofibroblasts can revert to a phenotype similar to their precursors suggests that their dedifferentiation may be subject to manipulation to promote fibrosis resolution. BMP7 can inhibit liver and lung fibrosis and reverse kidney fibrosis in experimental models, in part by antagonizing TGF- $\beta 1$ functions and causing reversal of the myofibroblast phenotype (122-124). Overexpression of FGF- 1 attenuates TGF- $\beta 1$-induced lung fibrosis and can reverse the myofibroblast phenotype by downregulating $\alpha \mathrm{SMA}$ expression $(125,126)$. In lung fibroblasts, prostaglandin $\mathrm{E}_{2}$ $\left(\mathrm{PGE}_{2}\right)$ was shown to block TGF- $\beta 1$ - and ET-1-induced myofibroblast differentiation and induce dedifferentiation of myofibroblasts through inhibition of FAK activation $(127,128)$. However, the efficacy of inducing myofibroblast reversion pharmacologically in vivo for fibrosis resolution is unclear. For example, administration of $\mathrm{PGE}_{2}$ in mice subjected to bleomycin exposure failed to engender therapeutic effects (129). Likewise, although activation of nuclear factor erythroid 2-related factor 2 (NRF2) can increase antioxidant defenses and induce myofibroblast dedifferentiation in vitro, administration of the NRF2 activator sulforaphane did not protect mice from bleomycin-induced pulmonary fibrosis (130).
Myofibroblast reprogramming: potential route of fibrosis resolution. Recent studies have demonstrated remarkable cellular plasticity in myofibroblasts, and differentiated cells can dedifferentiate or transdifferentiate into other cell types, either physiologically or under experimental manipulation $(131,132)$. Although lineage reprogramming has long been observed in amphibians during injury repair, it was demonstrated only recently that mammalian skin myofibroblasts can undergo reprogramming for tissue regeneration (133). This process requires BMP ligands supplied by hair follicles present in close proximity. Human keloid fibroblasts cultured in the presence of BMP4 or human scalp hair follicles can be induced to become lipid-laden adipocytes, suggesting the potential of manipulating myofibroblast reprogramming to accelerate fibrosis resolution (133). The feasibility of reprogramming fibroblasts in vivo to promote tissue regeneration and reduce fibrosis has been shown in the heart, where fibroblasts can be directly reprogrammed to cardiomyocytes by expressing certain transcription factors (GATA4, HAND2, MEF2, and TBX5) $(134,135)$. Moreover, cardiac fibroblast reprogramming reduced LAD ligation-induced fibrosis (134). More recent studies have shown that hepatic myofibroblasts can be reprogrammed into hepatocyte-like cells to promote fibrosis resolution $(136,137)$. Using either an adeno-associated viral vector (AAV6) that preferentially targets liver myofibroblasts to express six murine transcription factors (HNF1A, HNF4A, FOXA1, FOXA2, FOXA3, FOXA4) (136), or targeted expression of four human transcription factors (FOXA3, HNF1A, HNF4A, GATA4) in hepatic myofibroblasts (137), some of the transduced hepatic myofibroblasts underwent conversion to hepatocytes, albeit at low efficiency $(\sim 4 \%)$. In vivo reprogramming of myofibroblasts was able to attenuate hepatic fibrosis induced by up to 8 weeks of repeated $\mathrm{CCl}_{4}$ injections, but was unable to resolve severe fibrosis developed after 12 weeks of $\mathrm{CCl}_{4}$ injections in a mouse model of cirrhosis $(136,137)$. Thus, even a rather low efficiency of myofibroblast reprogramming can produce beneficial antifibrotic effects. Notably, a fate-tracing study did not observe the transdifferentiation of hepatic myofibroblasts into hepatocytes during spontaneous resolution of $\mathrm{CCl}_{4}$-induced liver fibrosis (116), further suggesting that spontaneous lineage reprogramming rarely occurs, if at all. Nevertheless, in vivo lineage reprogramming may represent a promising therapeutic approach $(138,139)$.

\section{Conclusions and perspectives}

Production of ECM and subsequent remodeling of the provisional matrix are components of normal wound healing. Therefore, it may be possible to harness and amplify the endogenous mechanisms of matrix resolution to treat organ fibrosis, which develops largely due to repeated or chronic injuries. Eradication of the underlying deleterious stimuli is perhaps the most effective strategy toward fibrosis resolution. Where treating the root cause of fibrosis is not possible, it appears that elimination of fibrogenic myofibroblasts is a promising approach. Current information indicates that myofibroblasts can be removed through several alternative cell fates: apoptosis, senescence, dedifferentiation, and reprogramming. It is presently unclear how the specific cell fate of myofibroblasts in a given context is determined, and understanding this aspect will be a significant advance. Accumulating evidence indicates that autophagy, a cellular pathway of organelle and protein degradation, can 
influence the determination of cell fate, including apoptosis, senescence, differentiation, and reprogramming (140-143). Autophagy is known to play either an enhancing or an inhibitory role in fibrosis depending on the target cell type through selective degradation of cellular components (144-146). For example, autophagy in HSCs promotes their fibrogenic activation (147), whereas autophagy in macrophages and hepatocytes is antifibrotic by reducing injury-induced inflammation $(148,149)$. Further studies into genetic or pharmacological manipulations that can dictate specific myofibroblast cell fate may help achieve therapeutic objectives (Table 2).

In animal models of fibrosis and in human liver fibrosis where resolution is clearly documented, restoration of the parenchymal tissue is also observed. However, it is unclear whether fibrosis resolution and parenchymal restitution are mechanistically linked. It is plausible that fibrosis resolution promotes parenchymal repair, which may in turn signal to accelerate or dampen fibrosis resolution. Ideally, the rate of fibrosis resolution should be coordinated with parenchymal regeneration, since removal of the fibrotic scar without concomitant replacement with parenchyma may result in weakened tissue structure and potentially cause rupture. This coordination is particularly important in organs in which the regenerative capacity of the parenchyma is limited. Little is known about the possible crosstalk between fibrosis resolution and parenchymal regeneration, and elucidation of this interaction will be important in future studies.
Since mammalian aging is associated with reduced tissue regeneration (150) and increased risk and severity of fibrotic diseases (151, 152), targeting molecular alterations associated with aging may lead to reversal of persistent fibrosis in some instances (109).

Current treatments for fibrosis are extremely limited. A major challenge is that animal models do not fully recapitulate human pathology in fibrotic diseases, and preclinical models are often not predictive of the efficacies of novel therapies in humans. In this regard, substantial progress is being made in the development of mouse models with humanized immune system or parenchymal tissue $(153,154)$, some of which have been used for studying specific aspects of fibrosis (155-158). Although significant challenges still remain in the application of these experimental systems, the development of improved animal models will likely lead to new insights into the resolution of fibrosis.

\section{Acknowledgments}

This work was supported by NIH grants R01AR061791, R01DK108994, and R01GM078492 to LFL.

Address correspondence to: Lester F. Lau, Department of Biochemistry and Molecular Genetics, University of Illinois at Chicago College of Medicine, 900 South Ashland Avenue, Chicago, Illinois 60607, USA. Phone: 312.996.6978; E-mail: LFLau@uic.edu.
1. Rockey DC, Bell PD, Hill JA. Fibrosis - a common pathway to organ injury and failure. $N$ Engl $J$ Med. 2015;372(12):1138-1149.

2. Wynn TA. Fibrotic disease and the $\mathrm{T}(\mathrm{H}) 1 / \mathrm{T}(\mathrm{H}) 2$ paradigm. Nat Rev Immunol. 2004;4(8):583-594.

3. Stramer BM, Mori R, Martin P. The inflammation-fibrosis link? A Jekyll and Hyde role for blood cells during wound repair. J Invest Dermatol.2007;127(5):1009-1017.

4. Gurtner GC, Werner S, Barrandon Y, Longaker MT. Wound repair and regeneration. Nature. 2008;453(7193):314-321.

5. Hochreiter-Hufford A, Ravichandran KS. Clearing the dead: apoptotic cell sensing, recognition, engulfment, and digestion. Cold Spring Harb Perspect Biol. 2013;5(1):a008748.

6. Kisseleva T, Brenner DA. Fibrogenesis of parenchymal organs. Proc Am Thorac Soc. 2008;5(3):338-342.

7. Wynn TA, Vannella KM. Macrophages in tissue repair, regeneration, and fibrosis. Immunity. 2016;44(3):450-462.

8. Bochaton-Piallat ML, Gabbiani G, Hinz B. The myofibroblast in wound healing and fibrosis: answered and unanswered questions. F1000Res. 2016;5:F1000 Faculty Rev-752.

9. Serini G, et al. The fibronectin domain ED-A is crucial for myofibroblastic phenotype induction by transforming growth factor-beta1. J Cell Biol. 1998;142(3):873-881.

10. Darby IA, Zakuan N, Billet F, Desmoulière A. The myofibroblast, a key cell in normal and pathological tissue repair. Cell Mol Life Sci. 2016;73(6):1145-1157.

11. Wells RG, Schwabe RF, Schwabe R. Origin and function of myofibroblasts in the liver. Semin Liver Dis. 2015;35(2):97-106.
12. Tallquist MD, Molkentin JD. Redefining the identity of cardiac fibroblasts. Nat Rev Cardiol. 2017;14(8):484-491.

13. Kramann R, et al. Perivascular $\mathrm{Gli1}^{+}$progenitors are key contributors to injury-induced organ fibrosis. Cell Stem Cell. 2015;16(1):51-66.

14. El Agha E, et al. Mesenchymal stem cells in fibrotic disease. Cell Stem Cell. 2017;21(2):166-177.

15. Koyama Y, Brenner DA. Liver inflammation and fibrosis. J Clin Invest. 2017;127(1):55-64.

16. Tsuchida T, Friedman SL. Mechanisms of hepatic stellate cell activation. Nat Rev Gastroenterol Hepatol. 2017;14(7):397-411.

17. Liaw YF. Reversal of cirrhosis: an achievable goal of hepatitis B antiviral therapy. J Hepatol. 2013;59(4):880-881.

18. Marcellin P, et al. Regression of cirrhosis during treatment with tenofovir disoproxil fumarate for chronic hepatitis B: a 5-year open-label follow-up study. Lancet. 2013;381(9865):468-475.

19. Bachofner JA, et al. Direct antiviral agent treatment of chronic hepatitis $C$ results in rapid regression of transient elastography and fibrosis markers fibrosis- 4 score and aspartate aminotransferase-platelet ratio index. Liver Int . 2017;37(3):369-376

20. Andrade ZA. Schistosomiasis and hepatic fibrosis regression. Acta Trop. 2008;108(2-3):79-82.

21. Richter J, et al. Severe liver fibrosis caused by Schistosoma mansoni: management and treatment with a transjugular intrahepatic portosystemic shunt. Lancet Infect Dis. 2015;15(6):731-737.

22. Mederacke I, et al. Fate tracing reveals hepatic stellate cells as dominant contributors to liver fibrosis independent of its aetiology. Nat Commun. 2013;4:2823.

23. Iwaisako $\mathrm{K}$, et al. Origin of myofibroblasts in the fibrotic liver in mice. Proc Natl Acad Sci U S A. 2014;111(32):E3297-E3305.

24. Li Y, Wang J, Asahina K. Mesothelial cells give rise to hepatic stellate cells and myofibroblasts via mesothelial-mesenchymal transition in liver injury. Proc Natl Acad Sci U S A. 2013;110(6):2324-2329.

25. Murray LA, Rubinowitz A, Herzog EL. Interstitial lung disease: is interstitial lung disease the same as scleroderma lung disease? Curr Opin Rheumatol. 2012;24(6):656-662.

26. Karimi-Shah BA, Chowdhury BA. Forced vital capacity in idiopathic pulmonary fibrosis - FDA review of pirfenidone and nintedanib. $N$ Engl J Med. 2015;372(13):1189-1191.

27. Moore BB, Lawson WE, Oury TD, Sisson TH, Raghavendran K, Hogaboam CM. Animal models of fibrotic lung disease. Am J Respir Cell Mol Biol. 2013;49(2):167-179.

28. Zolak JS, et al. Pleural mesothelial cell differentiation and invasion in fibrogenic lung injury. $A m$ Pathol.2013;182(4):1239-1247.

29. Rock JR, et al. Multiple stromal populations contribute to pulmonary fibrosis without evidence for epithelial to mesenchymal transition. Proc Natl Acad Sci U S A. 2011;108(52):E1475-E1483.

30. Hung C, et al. Role of lung pericytes and resident fibroblasts in the pathogenesis of pulmonary fibrosis. Am J Respir Crit Care Med. 2013;188(7):820-830.

31. El Agha E, et al. Two-way conversion between lipogenic and myogenic fibroblastic phenotypes marks the progression and resolution of lung fibrosis. Cell Stem Cell. 2017;20(2):261-273.e3.

32. Liu Y. Cellular and molecular mechanisms of renal fibrosis. Nat Rev Nephrol. 2011;7(12):684-696.

33. Kaissling B, Lehir M, Kriz W. Renal epitheli- 
al injury and fibrosis. Biochim Biophys Acta. 2013;1832(7):931-939.

34. Fioretto P, Steffes MW, Sutherland DE, Goetz FC, Mauer M. Reversal of lesions of diabetic nephropathy after pancreas transplantation. N Engl J Med. 1998;339(2):69-75.

35. Fioretto P, Sutherland DE, Najafian B, Mauer $M$. Remodeling of renal interstitial and tubular lesions in pancreas transplant recipients. Kidney Int. 2006;69(5):907-912.

36. Duffield JS. Cellular and molecular mechanisms in kidney fibrosis. JClin Invest. 2014;124(6):2299-2306.

37. Nogueira A, Pires MJ, Oliveira PA. Pathophysiological mechanisms of renal fibrosis: a review of animal models and therapeutic strategies. In Vivo. 2017;31(1):1-22.

38. LeBleu VS, et al. Origin and function of myofibroblasts in kidney fibrosis. Nat Med. 2013;19(8):1047-1053.

39. Grande MT, et al. Snail1-induced partial epithelial-to-mesenchymal transition drives renal fibrosis in mice and can be targeted to reverse established disease. Nat Med. 2015;21(9):989-997.

40. Lovisa S, et al. Epithelial-to-mesenchymal transition induces cell cycle arrest and parenchymal damage in renal fibrosis. Nat Med. 2015;21(9):998-1009.

41. Travers JG, Kamal FA, Robbins J, Yutzey KE, Blaxall BC. Cardiac fibrosis: the fibroblast awakens. Circ Res. 2016;118(6):1021-1040.

42. Brilla CG, Funck RC, Rupp H. Lisinopril-mediated regression of myocardial fibrosis in patients with hypertensive heart disease. Circulation. 2000;102(12):1388-1393.

43. Díez J, Querejeta R, López B, González A, Larman M, Martínez Ubago JL. Losartan-dependent regression of myocardial fibrosis is associated with reduction of left ventricular chamber stiffness in hypertensive patients. Circulation. 2002;105(21):2512-2517.

44. Szardien S, et al. Regression of cardiac hypertrophy by granulocyte colony-stimulating factor-stimulated interleukin-1 $\beta$ synthesis. Eur Heart J. 2012;33(5):595-605.

45. Brilla CG. Regression of myocardial fibrosis in hypertensive heart disease: diverse effects of various antihypertensive drugs. Cardiovasc Res. 2000;46(2):324-331.

46. Tyralla K, et al. High-dose enalapril treatment reverses myocardial fibrosis in experimental uremic cardiomyopathy. PLoS One. 2011;6(1):e15287.

47. Kanisicak O, et al. Genetic lineage tracing defines myofibroblast origin and function in the injured heart. Nat Commun. 2016;7:12260.

48. Pinto AR, et al. Revisiting cardiac cellular composition. Circ Res. 2016;118(3):400-409.

49. Karsdal MA, et al. Novel insights into the function and dynamics of extracellular matrix in liver fibrosis. Am J Physiol Gastrointest Liver Physiol. 2015;308(10):G807-G830.

50. Issa R, et al. Mutation in collagen- 1 that confers resistance to the action of collagenase results in failure of recovery from CCl4-induced liver fibrosis, persistence of activated hepatic stellate cells, and diminished hepatocyte regeneration.
FASEB J. 2003;17(1):47-49.

51. McKleroy W, Lee TH, Atabai K. Always cleave up your mess: targeting collagen degradation to treat tissue fibrosis. Am J Physiol Lung Cell Mol Physiol. 2013;304(11):L709-L721.

52. Iimuro $Y$, et al. Delivery of matrix metalloproteinase-1 attenuates established liver fibrosis in the rat. Gastroenterology. 2003;124(2):445-458.

53. Foronjy RF, Sun J, Lemaitre V, D’Armiento JM. Transgenic expression of matrix metalloproteinase-1 inhibits myocardial fibrosis and prevents the transition to heart failure in a pressure overload mouse model. Hypertens Res. 2008;31(4):725-735.

54. Kaar JL, et al. Matrix metalloproteinase-1 treatment of muscle fibrosis. Acta Biomater. 2008;4(5):1411-1420.

55. Giannandrea M, Parks WC. Diverse functions of matrix metalloproteinases during fibrosis. Dis Model Mech. 2014;7(2):193-203.

56. Khokha R, Murthy A, Weiss A. Metalloproteinases and their natural inhibitors in inflammation and immunity. Nat Rev Immunol. 2013;13(9):649-665.

57. Yoshiji $\mathrm{H}$, et al. Tissue inhibitor of metalloproteinases-1 promotes liver fibrosis development in a transgenic mouse model. Hepatology. 2000;32(6):1248-1254.

58. Wang H, Lafdil F, Wang L, Yin S, Feng D, Gao B. Tissue inhibitor of metalloproteinase 1 (TIMP-1) deficiency exacerbates carbon tetrachlorideinduced liver injury and fibrosis in mice: involvement of hepatocyte STAT3 in TIMP-1 production. Cell Biosci. 2011;1(1):14.

59. Gill SE, et al. Tissue inhibitor of metalloproteinases 3 regulates resolution of inflammation following acute lung injury. Am J Pathol. 2010;176(1):64-73.

60. Stetler-Stevenson WG. Tissue inhibitors of metalloproteinases in cell signaling: metalloproteinase-independent biological activities. Sci Signal. 2008;1(27):re6.

61. Yamauchi M, Sricholpech M. Lysine post-translational modifications of collagen. Essays Biochem. 2012;52:113-133.

62. Barry-Hamilton V, et al. Allosteric inhibition of lysyl oxidase-like-2 impedes the development of a pathologic microenvironment. Nat Med. 2010;16(9):1009-1017.

63. Yang J, et al. Targeting LOXL2 for cardiac interstitial fibrosis and heart failure treatment. Nat Commun. 2016;7:13710.

64. Ikenaga N, et al. Selective targeting of lysyl oxidase-like 2 (LOXL2) suppresses hepatic fibrosis progression and accelerates its reversal. Gut. 2017;66(9):1697-1708.

65. Raghu G, et al. Efficacy of simtuzumab versus placebo in patients with idiopathic pulmonary fibrosis: a randomised, double-blind, controlled, phase 2 trial. Lancet Respir Med. 2017;5(1):22-32.

66. Olsen $\mathrm{KC}$, et al. Transglutaminase 2 and its role in pulmonary fibrosis. Am J Respir Crit Care Med. 2011;184(6):699-707.

67. Popov Y, et al. Tissue transglutaminase does not affect fibrotic matrix stability or regression of liver fibrosis in mice. Gastroenterology. 2011;140(5):1642-1652.

68. Bundesmann MM, Wagner TE, Chow YH, Alte- meier WA, Steinbach T, Schnapp LM. Role of urokinase plasminogen activator receptor-associated protein in mouse lung. Am J Respir Cell Mol Biol. 2012;46(2):233-239.

69. Atabai K, et al. Mfge8 diminishes the severity of tissue fibrosis in mice by binding and targeting collagen for uptake by macrophages. J Clin Invest. 2009;119(12):3713-3722.

70. Deroide N, et al. MFGE8 inhibits inflammasome-induced IL-1 $\beta$ production and limits postischemic cerebral injury. JClin Invest. 2013;123(3):1176-1181.

71. Hanayama R, Tanaka M, Miwa K, Shinohara A, Iwamatsu A, Nagata S. Identification of a factor that links apoptotic cells to phagocytes. Nature. 2002;417(6885):182-187.

72. Duffield JS, et al. Selective depletion of macrophages reveals distinct, opposing roles during liver injury and repair. J Clin Invest. 2005;115(1):56-65.

73. Ramachandran P, et al. Differential Ly-6C expression identifies the recruited macrophage phenotype, which orchestrates the regression of murine liver fibrosis. Proc Natl Acad Sci U S A. 2012;109(46):E3186-E3195.

74. Thomas JA, et al. Macrophage therapy for murine liver fibrosis recruits host effector cells improving fibrosis, regeneration, and function. Hepatol ogy. 2011;53(6):2003-2015.

75. Kantari-Mimoun C, et al. Resolution of liver fibrosis requires myeloid cell-driven sinusoidal angiogenesis. Hepatology. 2015;61(6):2042-2055.

76. Desmoulière A, Redard M, Darby I, Gabbiani G. Apoptosis mediates the decrease in cellularity during the transition between granulation tissue and scar. Am J Pathol. 1995;146(1):56-66.

77. Iredale JP, et al. Mechanisms of spontaneous resolution of rat liver fibrosis. Hepatic stellate cell apoptosis and reduced hepatic expression of metalloproteinase inhibitors. J Clin Invest. 1998;102(3):538-549.

78. McIlwain DR, Berger T, Mak TW. Caspase functions in cell death and disease. Cold Spring Harb Perspect Biol. 2013;5(4):a008656.

79. Wallach-Dayan SB, et al. Cutting edge: FasL(+) immune cells promote resolution of fibrosis. JAutoimmun. 2015;59:67-76.

80. Luo JL, Kamata H, Karin M. The anti-death machinery in IKK/NF- $\mathrm{kB}$ signaling. J Clin Immunol. 2005;25(6):541-550.

81. Kulasekaran P, Scavone CA, Rogers DS, Arenberg DA, Thannickal VJ, Horowitz JC. Endothelin-1 and transforming growth factor-beta1 independently induce fibroblast resistance to apoptosis via AKT activation. Am J Respir Cell Mol Biol. 2009;41(4):484-493.

82. Novo E, et al. Overexpression of Bcl-2 by activated human hepatic stellate cells: resistance to apoptosis as a mechanism of progressive hepatic fibrogenesis in humans. Gut. 2006;55(8):1174-1182.

83. Kisseleva T, et al. Myofibroblasts revert to an inactive phenotype during regression of liver fibrosis. Proc Natl Acad Sci U S A. 2012;109(24):9448-9453.

84. Zhou Y, et al. Inhibition of mechanosensitive signaling in myofibroblasts ameliorates experimental pulmonary fibrosis. J Clin Invest. 2013;123(3):1096-1108. 
85. Sisson TH, et al. Inhibition of myocardin-related transcription factor/serum response factor signaling decreases lung fibrosis and promotes mesenchymal cell apoptosis. Am J Pathol. 2015;185(4):969-986.

86. Douglass A, et al. Antibody-targeted myofibroblast apoptosis reduces fibrosis during sustained liver injury. J Hepatol. 2008;49(1):88-98.

87. Oakley F, et al. Angiotensin II activates I kappaB kinase phosphorylation of RelA at Ser 536 to promote myofibroblast survival and liver fibrosis. Gastroenterology. 2009;136(7):2334-2344.e1.

88. Anan A, Baskin-Bey ES, Bronk SF, Werneburg NW, Shah VH, Gores GJ. Proteasome inhibition induces hepatic stellate cell apoptosis. Hepatology. 2006;43(2):335-344.

89. Sanders YY, Hagood JS, Liu H, Zhang W, Ambalavanan N, Thannickal VJ. Histone deacetylase inhibition promotes fibroblast apoptosis and ameliorates pulmonary fibrosis in mice. Eur Respir J. 2014;43(5):1448-1458.

90. Ashley SL, et al. Targeting inhibitor of apoptosis proteins protects from bleomycin-induced lung fibrosis. Am J Respir Cell Mol Biol. 2016;54(4):482-492.

91. Jeong D, et al. Matricellular protein CCN5 reverses established cardiac fibrosis. J Am Coll Cardiol. 2016;67(13):1556-1568.

92. Rodier F, Campisi J. Four faces of cellular senescence. J Cell Biol. 2011;192(4):547-556.

93. Muñoz-Espín D, Serrano M. Cellular senescence: from physiology to pathology. Nat Rev Mol Cell Biol. 2014;15(7):482-496.

94. Tchkonia T, Zhu Y, van Deursen J, Campisi J, Kirkland JL. Cellular senescence and the senescent secretory phenotype: therapeutic opportunities. J Clin Invest. 2013;123(3):966-972.

95. Krizhanovsky V, et al. Senescence of activated stellate cells limits liver fibrosis. Cell. 2008;134(4):657-667.

96. Jun JI, Lau LF. The matricellular protein CCN1 induces fibroblast senescence and restricts fibrosis in cutaneous wound healing. Nat Cell Biol. 2010;12(7):676-685.

97. Kang TW, et al. Senescence surveillance of pre-malignant hepatocytes limits liver cancer development. Nature. 2011;479(7374):547-551.

98. Egashira M, et al. F4/80+ macrophages contribute to clearance of senescent cells in the mouse postpartum uterus. Endocrinology. 2017;158(7):2344-2353.

99. Jun JI, Lau LF. Taking aim at the extracellular matrix: CCN proteins as emerging therapeutic targets. Nat Rev Drug Discov. 2011;10(12):945-963.

100.Lau LF. CCN1/CYR61: the very model of a modern matricellular protein. Cell Mol Life Sci. 2011;68(19):3149-3163.

101. Kim KH, Chen CC, Monzon RI, Lau LF. Matricellular protein $\mathrm{CCN} 1$ promotes regression of liver fibrosis through induction of cellular senescence in hepatic myofibroblasts. Mol Cell Biol. 2013;33(10):2078-2090.

102. Borkham-Kamphorst E, et al. The anti-fibrotic effects of CCN1/CYR61 in primary portal myofibroblasts are mediated through induction of reactive oxygen species resulting in cellular senescence, apoptosis and attenuated TGF- $\beta$ signaling. Biochim Biophys Acta. 2014;1843(5):902-914.
103. Kong X, et al. Interleukin-22 induces hepatic stellate cell senescence and restricts liver fibrosis in mice. Hepatology. 2012;56(3):1150-1159.

104.Zhu F, et al. Senescent cardiac fibroblast is critical for cardiac fibrosis after myocardial infarction. PLoS One. 2013;8(9):e74535.

105. Meyer K, Hodwin B, Ramanujam D, Engelhardt $\mathrm{S}$, Sarikas A. Essential role for premature senescence of myofibroblasts in myocardial fibrosis. JAm Coll Cardiol. 2016;67(17):2018-2028.

106. Wolstein JM, Lee DH, Michaud J, Buot V, Stefanchik B, Plotkin MD. INK4a knockout mice exhibit increased fibrosis under normal conditions and in response to unilateral ureteral obstruction. $A m J$ Physiol Renal Physiol.2010;299(6):F1486-F1495.

107. Leung JY, et al. Sav1 loss induces senescence and Stat 3 activation coinciding with tubulointerstitial fibrosis. Mol Cell Biol. 2017;37(12):e00565-16.

108. Aoshiba K, et al. Senescence-associated secretory phenotype in a mouse model of bleomycin-induced lung injury. Exp Toxicol Pathol. 2013; 65(7-8):1053-1062.

109. Hecker L, et al. Reversal of persistent fibrosis in aging by targeting Nox4-Nrf2 redox imbalance. Sci Transl Med. 2014;6(231):231ra47.

110. Minagawa S, et al. Accelerated epithelial cell senescence in IPF and the inhibitory role of SIRT6 in TGF- $\beta$-induced senescence of human bronchial epithelial cells. Am J Physiol Lung Cell Mol Physiol. 2011;300(3):L391-L401.

111. Schafer MJ, et al. Cellular senescence mediates fibrotic pulmonary disease. Nat Commun. 2017;8:14532

112. Lehmann M, et al. Senolytic drugs target alveolar epithelial cell function and attenuate experimental lung fibrosis ex vivo. Eur Respir J 2017;50(2):1602367.

113. Cui H, et al. miR-34a inhibits lung fibrosis by inducing lung fibroblast senescence. Am J Respir Cell Mol Biol. 2017;56(2):168-178.

114. Cui H, et al. miR-34a promotes fibrosis in aged lungs by inducing alveolarepithelial dysfunctions. Am J Physiol Lung Cell Mol Physiol. 2017;312(3):L415-L424.

115. Pardo A, Selman M. Fibroblast senescence and apoptosis. "One-two punch" to slow down lung fibrosis? Am J Respir Cell Mol Biol. 2017;56(2):145-146.

116. Troeger JS, et al. Deactivation of hepatic stellate cells during liver fibrosis resolution in mice. Gastroenterology. 2012;143(4):1073-1083.e22.

117. She H, Xiong S, Hazra S, Tsukamoto H. Adipogenic transcriptional regulation of hepatic stellate cells. J Biol Chem. 2005;280(6):4959-4967.

118. Bitencourt S, et al. Capsaicin induces de-differentiation of activated hepatic stellate cell. Biochem Cell Biol. 2012;90(6):683-690.

119. Rehan VK, et al. Mechanism of nicotine-induced pulmonary fibroblast transdifferentiation. Am J Physiol Lung Cell Mol Physiol. 2005;289(4):L667-L676.

120. Rehan V, Torday J. Hyperoxia augments pulmonary lipofibroblast-to-myofibroblast transdifferentiation. Cell Biochem Biophys. 2003;38(3):239-250.

121. Reddy AT, Lakshmi SP, Zhang Y, Reddy RC. Nitrated fatty acids reverse pulmonary fibrosis by dedifferentiating myofibroblasts and promoting collagen uptake by alveolar macrophages. FASEB J
2014;28(12):5299-5310.

122.Zeisberg M, et al. BMP-7 counteracts TGF- $\beta 1$ induced epithelial-to-mesenchymal transition and reverses chronic renal injury. Nat Med. 2003;9(7):964-968.

123. Kinoshita K, et al. Adenovirus-mediated expression of BMP-7 suppresses the development of liver fibrosis in rats. Gut. 2007;56(5):706-714.

124. Midgley AC, et al. Hyaluronan regulates bone morphogenetic protein-7-dependent prevention and reversal of myofibroblast phenotype. J Biol Chem. 2015;290(18):11218-11234.

125. Maltseva O, Folger P, Zekaria D, Petridou S, Masur SK. Fibroblast growth factor reversal of the corneal myofibroblast phenotype. Invest Ophthalmol Vis Sci. 2001;42(11):2490-2495

126. Shimbori C, et al. Fibroblast growth factor-1 attenuates TGF- $\beta 1$-induced lung fibrosis. J Pathol. 2016;240(2):197-210.

127. Huang S, Wettlaufer SH, Hogaboam C, Aronoff DM, Peters-Golden M. Prostaglandin E(2) inhibits collagen expression and proliferation in patient-derived normal lung fibroblasts via E prostanoid 2 receptor and cAMP signaling. Am J Physiol Lung Cell Mol Physiol. 2007;292(2):L405-L413.

128. Garrison G, et al. Reversal of myofibroblast differentiation by prostaglandin E(2). Am J Respir Cell Mol Biol. 2013;48(5):550-558.

129. Dackor RT, et al. Prostaglandin $\mathrm{E}_{2}$ protects murine lungs from bleomycin-induced pulmonary fibrosis and lung dysfunction. Am J Physiol Lung Cell Mol Physiol. 2011;301(5):L645-L655.

130. Artaud-Macari E, et al. Nuclear factor erythroid 2-related factor 2 nuclear translocation induces myofibroblastic dedifferentiation in idiopathic pulmonary fibrosis. Antioxid Redox Signal. 2013;18(1):66-79.

131. Takahashi K, Yamanaka S. Induction of pluripotent stem cells from mouse embryonic and adult fibroblast cultures by defined factors. Cell. 2006;126(4):663-676.

132. Merrell AJ, Stanger BZ. Adult cell plasticity in vivo: de-differentiation and transdifferentiation are back in style. Nat Rev Mol Cell Biol. 2016;17(7):413-425.

133. Plikus MV, et al. Regeneration of fat cells from myofibroblasts during wound healing. Science. 2017;355(6326):748-752.

134.Song K, et al. Heart repair by reprogramming non-myocytes with cardiac transcription factors. Nature. 2012;485(7400):599-604.

135. Qian $\mathrm{L}$, et al. In vivo reprogramming of murine cardiac fibroblasts into induced cardiomyocytes. Nature. 2012;485(7400):593-598.

136. Rezvani $M$, et al. In vivo hepatic reprogramming of myofibroblasts with AAV vectors as a therapeutic strategy for liver fibrosis. Cell Stem Cell. 2016;18(6):809-816.

137. Song G, et al. Direct reprogramming of hepatic myofibroblasts into hepatocytes in vivo attenuates liver fibrosis. Cell Stem Cell. 2016;18(6):797-808.

138. Xu J, Du Y, Deng H. Direct lineage reprogramming: strategies, mechanisms, and applications. Cell Stem Cell. 2015;16(2):119-134.

139. Srivastava D, DeWitt N. In vivo cellular reprogramming: the next generation. Cell. 2016;166(6):1386-1396.

140.Green DR, Levine B. To be or not to be? How 
selective autophagy and cell death govern cell fate. Cell. 2014;157(1):65-75.

141. Mizushima N, Levine B. Autophagy in mammalian development and differentiation. Nat Cell Biol. 2010;12(9):823-830.

142.Wang S, Xia P, Rehm M, Fan Z. Autophagy and cell reprogramming. Cell Mol Life Sci. 2015;72(9):1699-1713.

143. Kang C, Elledge SJ. How autophagy both activates and inhibits cellular senescence. Autophagy. 2016;12(5):898-899.

144. Margaritopoulos GA, et al. Self-eating: friend or foe? The emerging role of autophagy in idiopathic pulmonary fibrosis. Biomed Res Int. 2013;2013:420497.

145. Mallat A, Lodder J, Teixeira-Clerc F, Moreau R, Codogno P, Lotersztajn S. Autophagy: a multifaceted partner in liver fibrosis. Biomed Res Int. 2014;2014:869390.

146.Gual P, Gilgenkrantz H, Lotersztajn S. Autophagy in chronic liver diseases: the two faces of Janus. Am J Physiol Cell Physiol. 2017;312(3):C263-C273.

147. Hernández-Gea V, et al. Autophagy releases lipid that promotes fibrogenesis by activated hepatic stellate cells in mice and in human tissues. Gastroenterology. 2012;142(4):938-946.

148. Lodder J, et al. Macrophage autophagy protects against liver fibrosis in mice. Autophagy. 2015;11(8):1280-1292.

149. Hidvegi T, et al. An autophagy-enhancing drug promotes degradation of mutant $\alpha 1$-antitryp$\sin \mathrm{Z}$ and reduces hepatic fibrosis. Science. 2010;329(5988):229-232.

150. Signer RA, Morrison SJ. Mechanisms that regulate stem cell aging and life span. Cell Stem Cell. 2013;12(2):152-165.

151. Kim IH, et al. Aging increases the susceptibility of hepatic inflammation, liver fibrosis and aging in response to high-fat diet in mice. Age (Dordr). 2016;38(4):291-302.

152. Mora AL, Bueno M, Rojas M. Mitochondria in the spotlight of aging and idiopathic pulmonary fibrosis. JClin Invest. 2017;127(2):405-414.

153. Walsh NC, et al. Humanized mouse models of clinical disease. Annu Rev Pathol. 2017;12:187-215.

154. Grompe M, Strom S. Mice with human livers. Gastroenterology. 2013;145(6):1209-1214.

155. Murray LA, et al. Targeting interleukin-13 with tralokinumab attenuates lung fibrosis and epithelial damage in a humanized SCID idiopathic pulmonary fibrosis model. Am J Respir Cell Mol Biol. 2014;50(5):985-994.

156. Bility MT, et al. Hepatitis B virus infection and immunopathogenesis in a humanized mouse model: induction of human-specific liver fibrosis and M2-like macrophages. PLoS Pathog. 2014;10(3):e1004032.

157. Bility MT, et al. Chronic hepatitis C infectioninduced liver fibrogenesis is associated with M2 macrophage activation. Sci Rep. 2016;6:39520.

158. Luchetti MM, et al. Induction of scleroderma fibrosis in skin-humanized mice by administration of anti-platelet-derived growth factor receptor agonistic autoantibodies. Arthritis Rheumatol. 2016;68(9):2263-2273.

159. Onozuka I, et al. Cholestatic liver fibrosis and toxin-induced fibrosis are exacerbated in matrix metalloproteinase-2 deficient mice. Biochem Biophys Res Commun. 2011;406(1):134-140.

160. Yamashita CM, et al. Matrix metalloproteinase 3 is a mediator of pulmonary fibrosis. Am J Pathol. 2011;179(4):1733-1745.

161. Zuo F, et al. Gene expression analysis reveals matrilysin as a key regulator of pulmonary fibrosis in mice and humans. Proc Natl Acad Sci U S A. 2002;99(9):6292-6297.

162.Siller-López F, et al. Treatment with human metalloproteinase-8 gene delivery ameliorates experimental rat liver cirrhosis. Gastroenterology. 2004;126(4):1122-1133; discussion 949.

163. Craig VJ, et al. Profibrotic activities for matrix metalloproteinase-8 during bleomycin-mediated lung injury. J Immunol. 2013;190(8):4283-4296.

164. Betsuyaku T, Fukuda Y, Parks WC, Shipley JM, Senior RM. Gelatinase B is required for alveolar bronchiolization after intratracheal bleomycin. Am J Pathol. 2000;157(2):525-535.

165. Cabrera S, et al. Overexpression of MMP9 in macrophages attenuates pulmonary fibrosis induced by bleomycin. Int $J$ Biochem Cell Biol. 2007;39(12):2324-2338.

166. Wang X, et al. Mice lacking the matrix metalloproteinase-9 gene reduce renal interstitial fibrosis in obstructive nephropathy. Am J Physiol Renal Physiol. 2010;299(5):F973-F982.

167. Manoury B, et al. Macrophage metalloelastase (MMP-12) deficiency does not alter bleomycin-induced pulmonary fibrosis in mice. J Inflamm (Lond). 2006;3:2.

168. Kang HR, Cho SJ, Lee CG, Homer RJ, Elias JA.
Transforming growth factor (TGF)- $\beta 1$ stimulates pulmonary fibrosis and inflammation via a Bax-dependent, bid-activated pathway that involves matrix metalloproteinase-12. J Biol Chem. 2007;282(10):7723-7732.

169. Abraham AP, Ma FY, Mulley WR, Ozols E, Nikolic-Paterson DJ. Macrophage infiltration and renal damage are independent of matrix metalloproteinase 12 in the obstructed kidney. Nephrolo$g y$ (Carlton). 2012;17(4):322-329.

170.Uchinami H, Seki E, Brenner DA, D’Armiento J. Loss of MMP 13 attenuates murine hepatic injury and fibrosis during cholestasis. Hepatology. 2006;44(2):420-429.

171. Endo H, et al. Matrix metalloproteinase-13 promotes recovery from experimental liver cirrhosis in rats. Pathobiology. 2011;78(5):239-252.

172. Sen AI, Shiomi T, Okada Y, D’Armiento JM. Deficiency of matrix metalloproteinase-13 increases inflammation after acute lung injury. Exp Lung Res. 2010;36(10):615-624.

173. Flechsig P, et al. Loss of matrix metalloproteinase-13 attenuates murine radiation-induced pulmonary fibrosis. Int J Radiat Oncol Biol Phys. 2010;77(2):582-590.

174. Jirouskova M, et al. Hepatoprotective effect of MMP-19 deficiency in a mouse model of chronic liver fibrosis. PLoS One. 2012;7(10):e46271.

175. Kim KH, et al. Tissue inhibitor of metalloproteinase-1 deficiency amplifies acute lung injury in bleomycin-exposed mice. Am J Respir Cell Mol Biol. 2005;33(3):271-279.

176. Kim H, et al. TIMP-1 deficiency does not attenuate interstitial fibrosis in obstructive nephropathy. J Am Soc Nephrol. 2001;12(4):736-748.

177. Hu YB, Li DG, Lu HM. Modified synthetic siRNA targeting tissue inhibitor of metalloproteinase-2 inhibits hepatic fibrogenesis in rats. J Gene Med. 2007;9(3):217-229.

178. Kawamoto H, et al. Tissue inhibitor of metalloproteinase-3 plays important roles in the kidney following unilateral ureteral obstruction. Hypertens Res. 2006;29(4):285-294.

179. Kassiri Z, et al. Loss of TIMP3 enhances interstitial nephritis and fibrosis. J Am Soc Nephrol. 2009;20(6):1223-1235.

180. Oakley F, et al. Inhibition of inhibitor of kappaB kinases stimulates hepatic stellate cell apoptosis and accelerated recovery from rat liver fibrosis. Gastroenterology. 2005;128(1):108-120. 